\title{
CD8 + Lymphocyte-Mediated Injury of Dorsal Root Ganglion Neurons during Lentivirus Infection: CD154-Dependent Cell Contact Neurotoxicity
}

\author{
Yu Zhu, ${ }^{1}$ Joseph Antony, ${ }^{2}$ Shuhong Liu, ${ }^{2}$ Jose A. Martinez, ${ }^{2}$ Fabrizio Giuliani, ${ }^{1}$ Douglas Zochodne, ${ }^{2}$ and \\ Christopher Power ${ }^{1,2}$ \\ ${ }^{1}$ Department of Medicine, University of Alberta, Edmonton, Alberta, Canada T6G 2S2, and ${ }^{2}$ Department of Clinical Neuroscience, University of Calgary, \\ Calgary, Alberta, Canada T2N 1N4
}

\begin{abstract}
Neuronal damage in dorsal root ganglia (DRGs) with accompanying axonal injury is a key feature of human immunodeficiency virus (HIV)-related distal sensory polyneuropathy (DSP). In a model of HIV-related DSP, we observed numerous CD3 + T lymphocytes $(p<$ 0.05) in DRGs from feline immunodeficiency virus (FIV)-infected animals, which also exhibited low CD4+ and high CD8+ lymphocyte levels in blood accompanied by a selective loss of small-diameter sural nerve axons $(p<0.05)$. FIV-infected lymphocytes cocultured with syngeneic DRGs caused neuronal damage, indicated by neurite retraction, neuronal soma atrophy, and loss $(p<0.05)$. In contrast, supernatants from FIV-infected or uninfected lymphocytes were minimally neurotoxic, despite high FIV virion levels. Among lymphocyte subsets cocultured with DRG cultures, CD8 + T cells from both FIV-infected and uninfected lymphocytes selectively caused DRG neuronal injury $(p<0.05)$. FIV-infected CD8 + T cells showed markedly increased CD154 expression $(p<0.05)$, whereas neurons were the predominant cells expressing CD40 in DRGs. Blocking CD154 on activated CD8 + T cells protected DRG neurons $(p<0.05)$. These findings indicated that CD8 + T cells were principal effectors of DRG neuronal injury after FIV infection through a CD40-CD154 interaction in a cell contact-dependent manner.
\end{abstract}

Key words: dorsal root ganglia; HIV; FIV; CD154; neuron; lymphocyte

\section{Introduction}

Distal sensory polyneuropathy (DSP) is the most common peripheral neuropathy among the human immunodeficiency virus (HIV-1)-infected individuals (Brinley et al., 2001; Verma, 2001) and is the most frequently encountered neurological disorder among HIV-infected patients in the developed world (Keswani and Hoke, 2003). DSP is characterized by sensory loss, spontaneous or evoked pain, paraesthesiae, and gait instability. Indeed, DSP substantially lowers the quality of life of people with HIV-1 infection, especially after the progression to acquired immunodeficiency syndrome (AIDS) (Pandya et al., 2005). The key neuropathological features of DSP include the loss of small-diameter axons together with the presence of inflammatory cells, comprised of infiltrating lymphocytes and activated macrophages within affected nerves and dorsal root ganglia (DRGs) (Bradley et al., 1998; Pardo et al., 2001). Previous studies have concentrated on the contributions of macrophage activation and the effects of

Received Nov. 7, 2005; revised Dec. 28, 2005; accepted Jan. 14, 2006.

This work was supported by the Canadian Institutes of Health Research (C.P.) and National Institutes of Health Grant IR 01 NS4626201 (C.P.). D.Z. is an Alberta Heritage Foundation for Medical Research Scientist. C.P. holds a Canada Research Chair (T1) in Neurological Infection and Immunity. We thank Drs. Ahmet Hoke and V. Wee Yong for helpful discussions and Aundria Hood for technical assistance.

Correspondence should be addressed to Dr. Christopher Power, Department of Medicine, University of Alberta, 611 Heritage Medical Research Centre, Edmonton, Alberta, Canada T6G 2S2. E-mail: chris.power@ualberta.ca. DOI:10.1523/JNEUROSCI.4767-05.2006

Copyright $\odot 2006$ Society for Neuroscience $\quad 0270-6474 / 06 / 263396-08 \$ 15.00 / 0$ inflammatory cytokines on DSP pathogenesis, which appear to be important pathogenic factors (Keswani and Hoke, 2003; Jones et al., 2005). However, little is known about the actions of the abundant lymphocyte population in DRGs of patients with HIVrelated DSP.

There is a growing literature demonstrating that activated $\mathrm{T}$ lymphocytes are cytotoxic to neurons (Medana et al., 2001b; Bien et al., 2002). Previous studies show that allogeneic T cells can kill mouse peripheral nervous system neurons (Manning et al., 1987), and antigen (Ag)-specific T cells are toxic to syngeneic mouse neurons on which major histocompatibility complex class I (MHC-I) expression was required (Rall et al., 1995; Medana et al., 2001a). More recent reports have revealed that activated $\mathrm{T}$ cells cocultured with human neurons or with mouse brain slices led to substantial neuronal death, regardless of whether the T cells were allogeneically and syngeneically derived (Rall et al., 1995; Medana et al., 2001a; Giuliani et al., 2003; Hannila and Kawaja, 2003). However, some studies have emphasized the point that cytotoxicity was mediated through cell contact-dependent mechanisms in which FasL, perforin, or CD154 and their cognate receptors were involved (Giuliani et al., 2003; Nitsch et al., 2004).

Feline immunodeficiency virus (FIV) is a lentivirus, like HIV, in the Retroviridae family, causing an AIDS-like illness in feline species, including domestic cats. Similar to the cell tropism of HIV, FIV infects feline macrophages, lymphocytes, and neural cells, including microglia and astrocytes (Brunner and Pedersen, 
1989; Dow et al., 1990), by means of the chemokine receptors CXCR4 and CCR5 (Willett et al., 1997; Johnston and Power, 2002). Similar to the clinical manifestations of HIV infection, FIV infection also leads to encephalopathy (Power et al., 1998) and peripheral neuropathy (Kennedy et al., 2004). Very recently, we developed a DRG culture system in which FIV caused neuronal injury and death (Zhu et al., 2005). Because FIV infection shares many similarities with HIV in terms of viral properties and pathogenic effects, FIV represents a useful animal model for extending the understanding of HIV pathogenesis. In the current study, we used the FIV model to investigate the extent to which FIV-infected and uninfected lymphocytes exerted cytopathic effects in DRG neurons. Indeed, our studies revealed that CD8 $+\mathrm{T}$ lymphocytes induced neuronal injury and death through a CD154-dependent mechanism.

\section{Materials and Methods}

Virus preparation. The FIV strain used in this study was the infectious neurovirulent recombinant molecular clone, $\mathrm{V1}$-Ch, derived by transfection of CrFK cells and amplification in feline peripheral blood mononuclear cells (PBMCs), as described previously (Johnston et al., 2000). Culture supernatants from FIV-infected feline PBMC, which served as sources of infectious virus for these experiments, were cleared of cellular debris by centrifugation and titered by limiting dilution, as described previously (Power et al., 1998).

Peripheral blood lymphocytes and FIV infection. Feline PBMCs were isolated from the blood of healthy retrovirus seronegative cats by FicollHypaque centrifugation, as described previously (Power et al., 1998), and suspended in RPMI 1640 medium (Invitrogen, Burlington, Ontario, Canada). To isolate lymphocytes, PBMCs were seeded in the flask for $4 \mathrm{~h}$ of adherence at $37^{\circ} \mathrm{C}, 5 \% \mathrm{CO}_{2}$, and then the suspended peripheral blood lymphocytes (PBLs) were counted and plated at $1.5 \times 10^{6}$ cells/well in 24-well plates with $5 \mathrm{ng} / \mathrm{ml}$ phytohemagglutinin. After $3 \mathrm{~d}$, half of the lymphocytes were infected with FIV $\left[10^{4}\right.$ tissue culture infectious dose (TCID) $/ \mathrm{ml}]$ at $37^{\circ} \mathrm{C}, 5 \% \mathrm{CO}_{2}$, and the media were changed after $24 \mathrm{~h}$. The remaining uninfected cells were used as controls. All of the cells were subsequently resuspended in AIM-V medium with different doses of phorbol myristate acetate [PMA; $0 \mathrm{ng} / \mathrm{ml}$ (P0), $5 \mathrm{ng} / \mathrm{ml}$ (P5), $25 \mathrm{ng} / \mathrm{ml}$ (P25), and $50 \mathrm{ng} / \mathrm{ml}$ (P50)] for a subsequent $3 \mathrm{~d}$ of differentiation.

Lymphocyte isolation. CD4+, CD8+, and CD22+ lymphocytes were isolated from the cultured feline PBLs above using Dynalbeads according to instructions of the manufacturer (Dynal Biotech, Oslo, Norway). Briefly, the PBLs were incubated with anti-feline CD4 and CD8 antibodies (Leukocyte Antigen Laboratory, University of California, Davis, CA), anti-feline CD4 and CD22 antibodies (Leukocyte Biology Laboratory), or anti-feline CD22 and CD8 monoclonal antibodies in PBS with $0.1 \%$ BSA for $30 \mathrm{~min}$. After washing, we treated cells with washed Dynalbeads labeled with anti-mouse antibodies to the cells for another $20 \mathrm{~min}$ at $4^{\circ} \mathrm{C}$ with gentle tilting and rotation. Tubes were then placed in a magnet for 2 min after a collection of the supernatant containing CD4, CD8, and CD22 lymphocytes, respectively (van Marle et al., 2002). The selected lymphocyte populations were confirmed by fluorescence-activated cell sorting (FACS) analyses, which revealed $>90 \%$ purity.

Flow cytometry analysis. Cultured PBLs were labeled with anti-feline CD22, anti-feline CD4, and anti-feline CD8 monoclonal antibodies and anti-human CD154 polyclonal antibody (Ab). FITC-conjugated goat anti-rabbit IgG Ab and PE conjugated goat anti-mouse IgG1 antibodies were applied after labeling of primary antibodies. Omitting the primary antibodies served as controls. Analysis was performed using the FACScan (Becton Dickinson, Mountain View, CA) flow cytometer. The cells $(1 \times$ $10^{4}$ ) were analyzed for each sample (Power et al., 1998).

Feline DRG cultures. Culture plates and chamber slides (Nunc, Naperville, IL) were coated with a 1:2 dilution (in media, v/v) of matrigel (BD Biosciences, Quebec, Canada). DRGs from FIV seronegative healthy adult cats were removed under a dissecting microscope (Zhu et al., 2005). Cleanly dissected DRGs were incubated at $37^{\circ} \mathrm{C}$ for $100 \mathrm{~min}$ in digestion media containing $0.5 \mathrm{mg} / \mathrm{ml}$ trypsin (Invitrogen), $1 \mathrm{mg} / \mathrm{ml}$ collagenase type IA (Sigma-Aldrich, Oakville, Ontario, Canada), and $0.1 \mathrm{mg} / \mathrm{ml}$ DNAase type I (Roche Products, Welwyn Garden City, UK) in DMEM (Sigma-Aldrich). Digestion media was removed by centrifuge at 1500 rpm for $5 \mathrm{~min}$, and cells were washed twice with culture medium [DMEM containing 10\% heat-inactivated fetal bovine serum, $5 \%$ horse serum (Invitrogen), 2 mM L-glutamine and $1 \% \mathrm{~N}-2$ supplement (Invitrogen), $0.1 \mathrm{mg} / \mathrm{ml}$ penicillin/streptomycin (Invitrogen), and 5\% L929 cellconditioned medium]. The tissue solution was triturated using a sterile glass pipette until a homogeneous cell suspension was obtained and adjusted to a concentration of $0.1 \times 10^{6} \mathrm{cells} / \mathrm{ml}$. Cells were seeded onto eight-well chamber slides $(250 \mu \mathrm{l} /$ well $)$ and incubated at $37^{\circ} \mathrm{C}, 5 \% \mathrm{CO}_{2}$. The next day and every third day thereafter, medium was changed.

Lymphocytes, antibody, or peptide treatment of cultured DRG cells. After $7 \mathrm{~d}$ of ex vivo differentiation, DRG cultures were treated with FIVinfected or uninfected syngeneic lymphocytes (with or without PMA stimulation) at $5 \times 10^{4}$ cells in each well or treated with $\mathrm{CD} 4+, \mathrm{CD} 8+$, or CD22+ lymphocyte subsets at the corresponding proportion of cells formed in total PBLs $\left(5 \times 10^{4}\right.$ cells $)$. After application of the lymphocytes, DRG cultures were vigorously washed with DMEM twice to remove nonadherent cells. In addition, the same number of CD8+ lymphocytes pretreated with anti-human CD154 antibody $(2 \mu \mathrm{g} / \mathrm{ml} ; \mathrm{BD}$ Biosciences, Franklin Lakes, NJ) for $1 \mathrm{~h}$ were also applied to DRG cultures. Recombinant human CD154 (200 ng/ml; Santa Cruz Biotechnology, Santa Cruz, CA) and anti-human CD154 antibody $(2 \mu \mathrm{g} / \mathrm{ml}$; BD Biosciences) were applied to the DRG cultures as controls. All of the treatments were maintained for $48 \mathrm{~h}$ and then fixed with $4 \%$ PBSbuffered paraformaldehyde for $15 \mathrm{~min}$.

Experimental animals and tissue collection. Specific pathogen-free neonatal (day 1) kittens were infected with $0.2 \mathrm{ml}$ of infectious $\left(10^{4} \mathrm{TCID}_{50} /\right.$ $\mathrm{ml}$ ) or heat-inactivated virus (control cats) in accordance with Canadian Animal Care Committee guidelines, as described previously (Power et al., 1998). Kittens were weaned at 6 weeks of age and monitored until 12 weeks of age, at which time all animals were killed, as described previously (Power et al., 1998; Kennedy et al., 2004), L5 DRGs were collected and fixed in $4 \%$ PBS-buffered paraformaldehyde for $12 \mathrm{~h}$ at $4^{\circ} \mathrm{C}$ and submerged in PBS containing $20 \%$ sucrose overnight at $4^{\circ} \mathrm{C}$ after wash in PBS. The fixed DRGs were embedded in OCT compound and fast frozen in isopentane with dry ice and stored at $-80^{\circ} \mathrm{C}$ until sectioned. L6 DRGs were immediately frozen on dry ice and kept at $-80^{\circ} \mathrm{C}$ until use.

Immunohistochemistry and immunofluorescence. PBS-buffered paraformaldehyde (4\%)-fixed cultured DRG cells on chamber slides and tissue sections were incubated with PBS containing 50\% normal goat serum overnight at $4^{\circ} \mathrm{C}$ to block nonspecific staining. The sections and slides were exposed either to mouse anti-microtubule-associated protein (MAP)-2 (clone HM-2; 1:1000 dilution; Sigma), rabbit anti-CD154 (1: 200 dilution; Santa Cruz Biotechnology), rabbit anti-CD40 (1:200 dilution; Santa Cruz Biotechnology), mouse anti-NF 200 (1:200 dilution; Sigma), or mouse anti-feline CD18 (1:10 dilution; Leukocyte Antigen Laboratory) overnight at $4^{\circ} \mathrm{C}$ followed by washing in PBS and then incubated with either Cy3 or Alexa 488-conjugated goat anti-rabbit or mouse (1:1000 dilution; Invitrogen, Eugene, OR) for $2 \mathrm{~h}$ at room temperature in the dark followed by repeated washing in PBS. The sections and slides were mounted with Gelvatol. The specificity of staining was confirmed by omitting the primary antibody. The sections and slides were examined on an Olympus FV300 confocal laser-scanning microscope and DIC microscope. In addition, a Zeiss (Oberkochen, Germany) Axioskop 2 upright microscope and Spot system (Diagnostic Instruments, Sterling Heights, MI) provided digital images for quantitative analysis of neurite length and neuronal soma size using the public domain program Scion Image (Scion, Frederick, MD).

Nerve morphology. Sural nerves were removed from 12-week-old FIVinfected and uninfected animals and processed for epon embedding ( $\mathrm{Zo-}$ chodne et al., 1997). Briefly, samples were fixed in $2.5 \%$ glutaraldehyde in $0.025 \mathrm{M}$ cacodylate buffer overnight, serially washed in $0.15 \mathrm{M}$ cacodylate buffer, postfixed in $2 \%$ osmium tetroxide in $0.12 \mathrm{~m}$ cacodylate, dehydrated using a series of graded alcohols and propylene oxide, and embedded in epon. Transverse sections $(1.0 \mu \mathrm{m}$ thick $) 15 \mathrm{~mm}$ distal to the sciatic trifurcation were cut with an ultramicrotome (Reichert, Austria) using glass knives and stained with toluidine blue. Morphological exam- 
ination of specimens was performed using Scion Image (Scion). Video images were obtained with a light microscope (Axioskope; Zeiss, Toronto, Ontario, Canada) and attached digital camera (Axiocam; Zeiss) interfaced with a computer. The computer-assisted image analysis allowed for the determination of the number, caliber, and size frequency of intact myelinated fibers. All counting was performed with the microscopist blinded to the identity of the animal group.

Quantitation of neuronal injury and loss. After completion of the immunolabeling protocol, slides were imaged for subsequent measurements of the neuronal soma area, maximal neurite length per neuron, using a minimum of 25-50 neurons per individual treatment from three separate wells by an examiner unaware of the slide identity. Using ScionImage image analysis software (Scion), each parameter was assessed, as reported previously (Hannila and Kawaja, 2003). In addition, cell survival was measured in terms of the number of MAP-2 immunopositive neurons per unit area in triplicate (Zhu et al., 2005). All experiments were repeated at least twice and performed in triplicate.

RNA extraction and cDNA synthesis. FIV-infected and uninfected PBLs with or without PMA stimulation and DRG tissues were homogenized and lysed in $1 \mathrm{ml}$ of Trizol (Invitrogen, Gaithersburg, MD) according to the guidelines of the manufacturer. Chloroform $(200 \mu \mathrm{l})$ was added and the tubes were shaken vigorously for $30 \mathrm{~s}$ followed by $2 \mathrm{~min}$ of incubation at room temperature. The samples were then centrifuged at 13,000 $\times g$ for $20 \mathrm{~min}$ at $4^{\circ} \mathrm{C}$. The upper phase $(450-500 \mu \mathrm{l})$ was transferred to a fresh tube. Isopropyl alcohol $(500 \mu \mathrm{l})$ was added to precipitate the total RNA at room temperature for $10 \mathrm{~min}$ followed by centrifugation at $13,000 \times g$ for $20 \mathrm{~min}$ at $4^{\circ} \mathrm{C}$. The resulting RNA pellets were washed with $75 \%$ ethanol. Total RNA was dissolved in diethylpyrocarbonate-treated water. RNA was treated with DNase $(2 \mu \mathrm{g} / \mathrm{ml}$; Invitrogen) in the presence of $20 \mathrm{U}$ of RNaseout (Invitrogen) at $37^{\circ} \mathrm{C}$ for $1 \mathrm{~h}$ followed by $10 \mathrm{~min}$ incubation at $70^{\circ} \mathrm{C}$, shown to be free of contaminating cellular DNA. cDNA was synthesized using $1 \mu \mathrm{g}$ of RNA, $5 \mu \mathrm{l}$ of $10 \mu \mathrm{m} \mathrm{dNTP,} 100 \mathrm{ng}$ of random primers (Roche, Laval, Quebec, Canada), $200 \mathrm{U}$ of Superscript (Invitrogen), and $20 \mathrm{U}$ of RNaseout (Invitrogen). Reactions were performed at $37^{\circ} \mathrm{C}$ for $90 \mathrm{~min}$ and $70^{\circ} \mathrm{C}$ for $15 \mathrm{~min}$. cDNA was stored at $-20^{\circ} \mathrm{C}$ until use, as reported previously (Power et al., 1998).

DNA extraction. CD8 + and CD4 + T cells with or without FIV infection were lysed in $200 \mu \mathrm{l}$ of SDS lysis solution at $50^{\circ} \mathrm{C}$ for $15 \mathrm{~min}$. Genomic DNA was extracted twice with an equal volume of Tris buffer phenol, $\mathrm{pH}$ 8.0, and centrifuged for $10 \mathrm{~min}$ at 13,000 rpm and once with an equal volume of chloroform:isoamyl alcohol (24:1) and centrifuged for $10 \mathrm{~min}$ at 13,000 $\mathrm{rpm}$. One-tenth volume $3 \mathrm{~m}$ sodium acetate, $\mathrm{pH} 4.8$, and three volumes of $100 \%$ ethanol were added, incubated at room temperature for $10 \mathrm{~min}$, and centrifuged for $15 \mathrm{~min}$ at 13,000 rpm. The pellets were washed with $70 \%$ ethanol. Total genomic DNA was dissolved in TE buffer.

Real-time PCR. Genomic DNA derived from cultured CD4+ and CD8 + T cells and RNA from the supernatants of FIV-infected and uninfected PBLs were used to amplify the viral pol gene for both proviral DNA in PBLs and viral RNA in PBL culture supernatant (Johnston et al., 2000). A real-time PCR protocol using primers that detect the FIV pol gene was used to determine the number of copies of viral RNA/ml as reported previously (Kennedy et al., 2004). Changes in RNA levels of specific host genes were quantified by real-time PCR using I-cycler IQ system (Bio-Rad, Mississauga, Ontario, Canada). cDNA prepared from total RNA of cultured T cells and DRG tissues was diluted 1:1 with sterile water, and $5 \mu \mathrm{l}$ was used per PCR. The primers used in the real-time PCR were as follows: glyceraldehyde-3-phosphate dehydrogenase (GAPDH): forward primer, 5'-AGC CTT CTC CAT GGT GGT GAA-3'; reverse primer, 5'-CGG AGT CAA CGG ATT TGG TCG-3'; CD154: forward primer, 5'-GGG GGC CTT ATC CTT ACT GAA CT-3'; reverse primer, $5^{\prime}$-GGA TCC TGG TCG CCT TTT TG-3' $\left(T_{\mathrm{m}} 50^{\circ} \mathrm{C}\right)$. Semiquantitative analysis was performed by monitoring in real-time the increase in fluorescence of SYBR-Green dye. Real-time fluorescence measurements were performed, and a threshold cycle value for CD154 gene was determined, as reported previously (Power et al., 2003). All data were normalized to the GAPDH mRNA threshold cycle level and expressed as mRNA relative fold change.

Statistical analysis. Statistical analyses were performed using Graph-
A

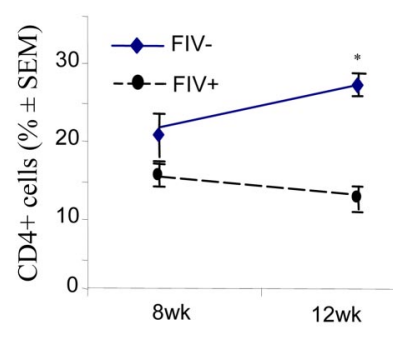

B
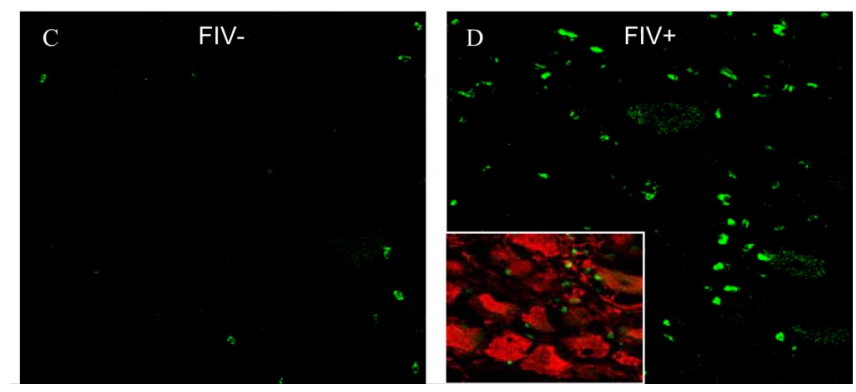

Figure 1. Blood lymphocyte subsets and CD3 + T cell infiltration in DRGs of FIV-infected animals. $\boldsymbol{A}$, Mean CD4 cell counts in blood were decreased in FIV-infected animals at 12 weeks after infection. $\boldsymbol{B}$, Mean CD8 cell counts in blood were increased in FIV-infected animals at 8 weeks (8wk) and 12 weeks (12wk) after infection compared with controls. Few CD3 + T cells were observed in DRGs of uninfected animals ( $C$, whereas CD3 $+\mathrm{T}$ cells were increased in DRGs of FIV-infected animals (D), often proximal to neurons (Student's $t$ test; ${ }^{*} p<0.05$ ).

Pad InStat version 3.0 (GraphPad Software, San Diego, CA) using ordinary ANOVA, together with post hoc Bonferroni multiple comparison test for histopathological changes and unpaired Student's $t$ test for mRNA alteration, viral load, and lymphocyte counts. $p$ values $<0.05$ were considered significant. Unless otherwise stated, all post hoc significant comparisons indicate differences between the control and individual treatment groups (i.e., FIV infection, PMA, or antibody treatments).

\section{Results}

Herein, we analyzed PBMCs isolated from FIV-infected and uninfected animals, revealing that the $\mathrm{CD} 4+\mathrm{T}$ cell population (Fig. $1 A$ ) was significantly decreased in FIV-infected animals at 12 weeks after infection compared with uninfected controls. Conversely, CD8 + T cells at both weeks 8 and 12 were significantly increased in FIV-infected animals compared with uninfected controls (Fig. $1 B$ ). In addition, axonal counts in sural nerves revealed that small-diameter fibers (axons 5-11 $\mu \mathrm{m}^{2}$ ) (mean \pm SEM) were significantly reduced in FIV-infected animals $(1079 \pm 21)$ compared with uninfected animals $(2105 \pm 25)$ $(p<0.05)$ and had a decline in their mean axonal area as well (data not shown), indicating additional atrophy, whereas largediameter fiber counts did not differ between groups (data not shown). The lymphocytes in the DRG from both FIV-infected and uninfected animals were analyzed by immunolabeling, which revealed numerous CD3 + immunopositive lymphocytes present in DRGs of FIV-infected animals (Fig. 1D) compared with those from uninfected animals (Fig. 1C). Quantitative analysis showed that there was a significant increase in the number of $\mathrm{CD} 3+$ immunopositive cells (mean $\pm \mathrm{SEM} / \mathrm{mm}^{2}$ ) in DRGs in FIV-infected compared with uninfected animals (544 \pm 47 vs $276 \pm 32 ; p<0.05)$. Thus, DRG infiltration by lymphocytes during FIV infection was associated with increased CD8 + lymphocytes in blood and loss of small-diameter sensory nerves.

Previous studies have shown DRG neuronal injury in patients with HIV-related DSP (Bradley et al., 1998) and in FIV-infected DRG cell cultures (Zhu et al., 2005). The findings of numerous 
lymphocytes present in the DRGs from FIV-infected cats suggested these infiltrating lymphocytes might contribute to the pathogenesis of DRG neuronal injury. Thus, we prepared syngeneic cultures from healthy cats in which PMA-stimulated and unstimulated PBLs with and without previous FIV infection were cocultured with healthy (uninfected) DRG cultures for $48 \mathrm{~h}$. Direct interactions were observed between neurons and lymphocytes (Fig. 2A), further defined by colocalization of NF 200 immunopositive neurons and their processes with CD3 $+\mathrm{T}$ cells (Fig. $2 B$ ). We then examined the morphological changes in DRG neurons induced by PBLs by assessing MAP-2 immunopositive neurons relative to untreated (control) cultures in terms of soma size, maximal neurite length, and neuronal survival. Quantitative analyses of neurite length revealed a PMA concentrationdependent decline in mean maximal neurite length in FIVinfected lymphocytes applied to DRG cultures compared with mock cultures, which was not evident for the uninfected cultures (Fig. 2C). Mean neuronal soma size was also significantly reduced in FIV-infected and uninfected lymphocytes after PMA $(25 \mu \mathrm{g} /$ $\mathrm{ml}$ ) stimulation relative to matched uninfected cultures at the same time point (Fig. 2D). Likewise, neuronal perikaryal numbers were significantly reduced in DRG cultures treated with FIVinfected PBLs compared with uninfected PBLs, although PMA treatment of PBLs had minimal effect on neuronal survival (Fig. $2 E$ ). In summary, whereas PBL activation in syngeneic lymphocyte-treated DRG cultures contributed to limited neurite retraction, FIV infection of PBLs markedly increased neurite retraction, neuronal soma atrophy, and loss.

To determine whether FIV-infected PBLs secreted neurotoxins, we treated DRG cultures with the supernatants from PMAstimulated PBLs for $48 \mathrm{~h}$ after FIV or mock infection. Although neurite retraction was not present in DRG cultures treated with the supernatants from FIV-infected and uninfected lymphocytes with or without PMA stimulation (Fig. $3 A$ ), a significant reduction in neuronal soma size was apparent in cultures treated with PMA-stimulated PBL supernatants compared with the unstimulated PBL-derived supernatants (Fig. 3B). However, no effect was observed on neuronal survival with the supernatant treatment from different lymphocyte cultures (Fig. 3C). We also examined FIV quantity in PBL-derived supernatants, which revealed that viral copy number was high in supernatants and unaffected by PMA treatment (Fig. 3D). Thus, these findings indicate that soluble factors, including virus particles from PBLs, contributed minimally to neuronal injury in this culture system, although PMA activation of lymphocytes may contribute to neuronal soma atrophy.

Previous studies indicate that specific PBL subsets were cytotoxic to different types of target cells (Ichiki et al., 2005; Riccieri et al., 2005). To further define which lymphocyte subsets contributed to the DRG neuronal injury, CD4+, CD8+, or CD22+ lymphocytes were isolated from FIV-infected and uninfected PBLs. Examination of ex vivo PBLs and CD4+, CD8+, and CD22+ lymphocytes (Fig. $4 A$ ) by flow cytometry assay showed that CD $4+\mathrm{T}$ cells represented the major fraction of activated and quiescent inactivated PBLs, regardless of the presence or absence of FIV infection. Not surprisingly, FIV provirus abundance was lower in CD8 + T cells compared with infected CD4+ T cells after stimulation with PMA, although unstimulated cells did not differ in provirus levels (Fig. 4B). After coculturing different PBL subsets with DRGs, CD4+ lymphocytes with or without FIV infection did not cause neurite retraction or neuronal soma atrophy (Fig. 4C,D). Likewise, CD22+ lymphocytes alone were not toxic to DRG neurons (Fig. 4E,F). However, CD8+ lymphocytes in-
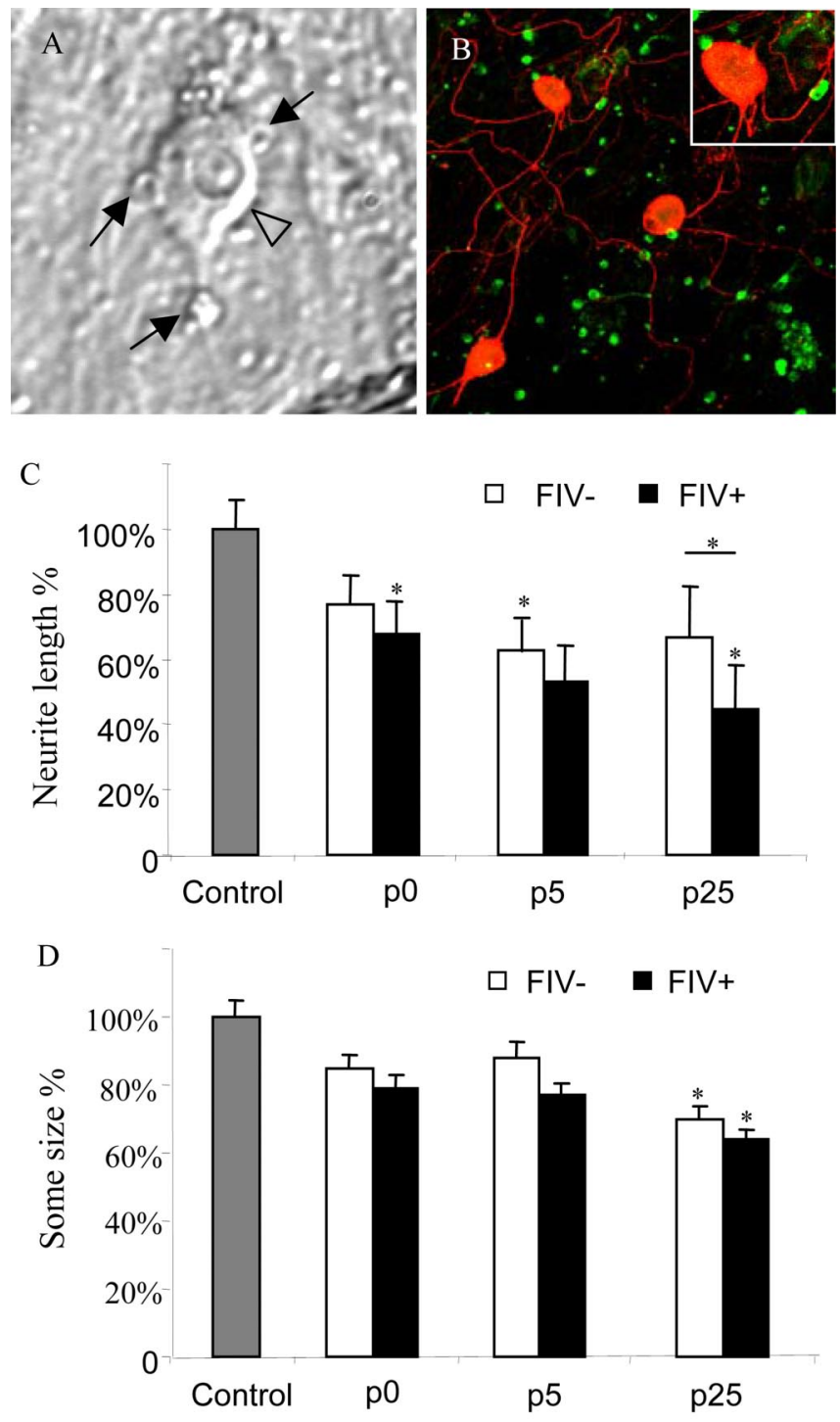

E

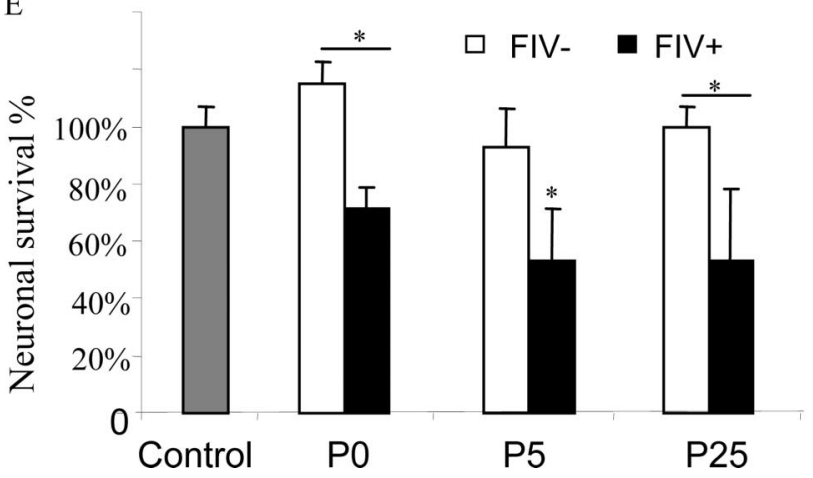

Figure 2. Interactions of peripheral blood lymphocytes with neurons and neurotoxicity. DIC imaging revealed T cells (arrows) interacted with neurons ( $\boldsymbol{A}$; arrowhead), which were defined by CD3 (green) and NF200 (red) immunostaining ( $\boldsymbol{B}$ ), respectively. $\boldsymbol{C}$, Neurite length was diminished in FIV-infected and uninfected T cell-treated DRG cultures compared with untreated controls $(185.7 \pm 17 \mu \mathrm{m})$ (mean \pm SEM), and FIV-infected T cells with PMA stimulation were more cytotoxic in terms of neurite length than uninfected $T$ cells. $\boldsymbol{D}$, Neuronal soma area was reduced with FIV-infected and uninfected T cell application, but only those T cells with $25 \mathrm{ng} / \mathrm{ml}$ PMA stimulation, regardless of FIV infection status, caused a significant reduction in soma size compared with untreated controls $\left(2220.8 \pm 105 \mu \mathrm{m}^{2}\right)$ (mean \pm SEM). $\boldsymbol{E}$, Neuronal loss caused by FIV-infected T cells was increased compared with uninfected $T$ cells and untreated controls (162 $\pm 16 /$ well; mean \pm SEM; Bonferroni's multiple comparison test; ${ }^{*} p<0.05$ ). 

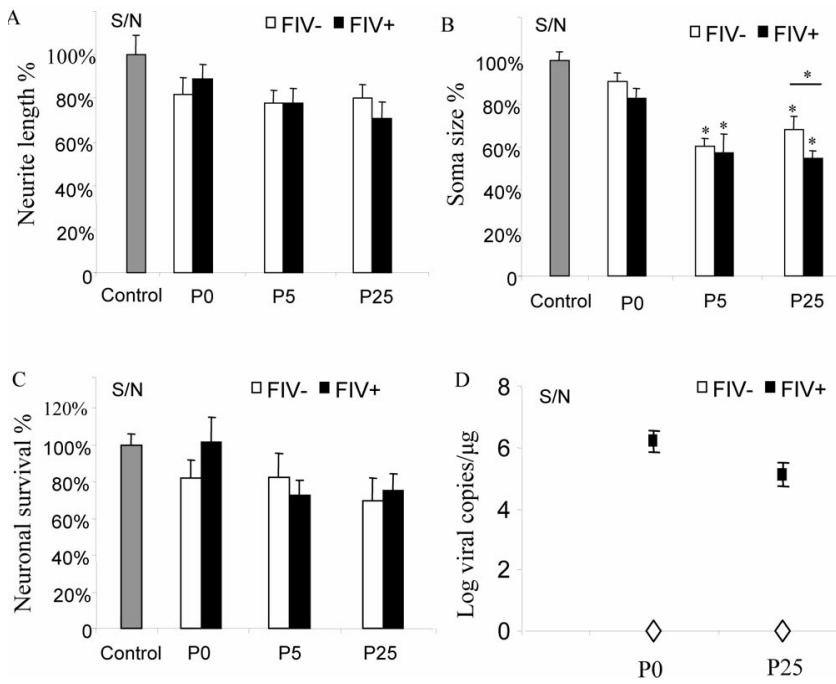

Figure 3. Application of PBL supernatants to DRG cultures. $A$, Supernatants from either FIV-infected or uninfected T cell cultures had no effects on neurite length (untreated control DRG cultures, $212 \pm 20 \mu \mathrm{m} ; \pm$ SEM). $\boldsymbol{B}$, Neuronal soma area was reduced by supernatant application from PMA-stimulated T cells compared with untreated controls, although supernatants from FIV-infected T cell cultures induced soma atrophy (untreated control DRG cultures, $2355 \pm 95 \mu \mathrm{m}^{2}$; mean \pm SEM). C, Neuronal survival was not affected by supernatants from FIV-infected and uninfected T cell cultures (neuron number in untreated control DRG cultures, $162.5 \pm 12.5$; mean \pm SEM). D, FIV RNA quantity in PBL culture supernatants displayed no differences between PMA-stimulated or unstimulated PBLs (Bonferroni's multiple comparison test; $\left.{ }^{*} p<0.05\right)$.

duced significant neuronal injury reflected by neurite length retraction (Fig. 4G) and soma atrophy (Fig. 4H), similar to the results of total lymphocyte application shown in Figure 2, $C$ and $D$. However, none of the individual PBL subsets caused neuronal loss in DRG cultures after $48 \mathrm{~h}$ of treatment (data not shown). These studies indicated that the CD8 $+\mathrm{T}$ lymphocyte was the predominant cell type causing neuronal injury, in particular neurite retraction.

Lymphocyte activation results in the enhanced expression of several molecules that mediate interactions between $\mathrm{T}$ cells and other cell types (Daoussis et al., 2004). Indeed, CD154 is a key determinant of T cell-mediated injury through its cognate receptor CD40 (Toubi and Shoenfeld, 2004). Moreover, CD40 is expressed on both neurons and macrophages (Tan et al., 2002). Although PMA stimulation caused more than a twofold downregulation of CD154 transcript levels in uninfected $\mathrm{T}$ cells by real-time PCR, FIV infection increased CD154 transcripts in T cells, especially within the PMA-stimulated groups (twofold to fivefold increases depending on the concentration of PMA applied), compared with FIV-uninfected T cell groups $(p<0.05)$ (Fig. 5A). To define which cells expressed CD154, we examined T cell subsets among FIV-infected and uninfected PBLs by FACS analyses, indicating that FIV infection increased expression of CD154 on CD8 + lymphocytes (20\%) compared with uninfected CD8 lymphocytes (14\%). Likewise, 3\% of FIV-infected CD4+ lymphocytes expressed CD154 compared with $2.2 \%$ of uninfected CD4+ lymphocytes (data not shown). Because CD154 expression was observed in FIV-infected PBLs, especially on CD8 + T cells, we examined its receptor, CD40, in DRGs. CD40 immunoreactive cells were present in DRGs from healthy and FIV-infected animals (Fig. 5B) and were principally colocalized with NF200 immunoreactivity on neurons (Fig. 5C). The number of CD18+ macrophages expressing CD40 detected in DRGs from FIV-infected animals was minimal (data not shown) com-
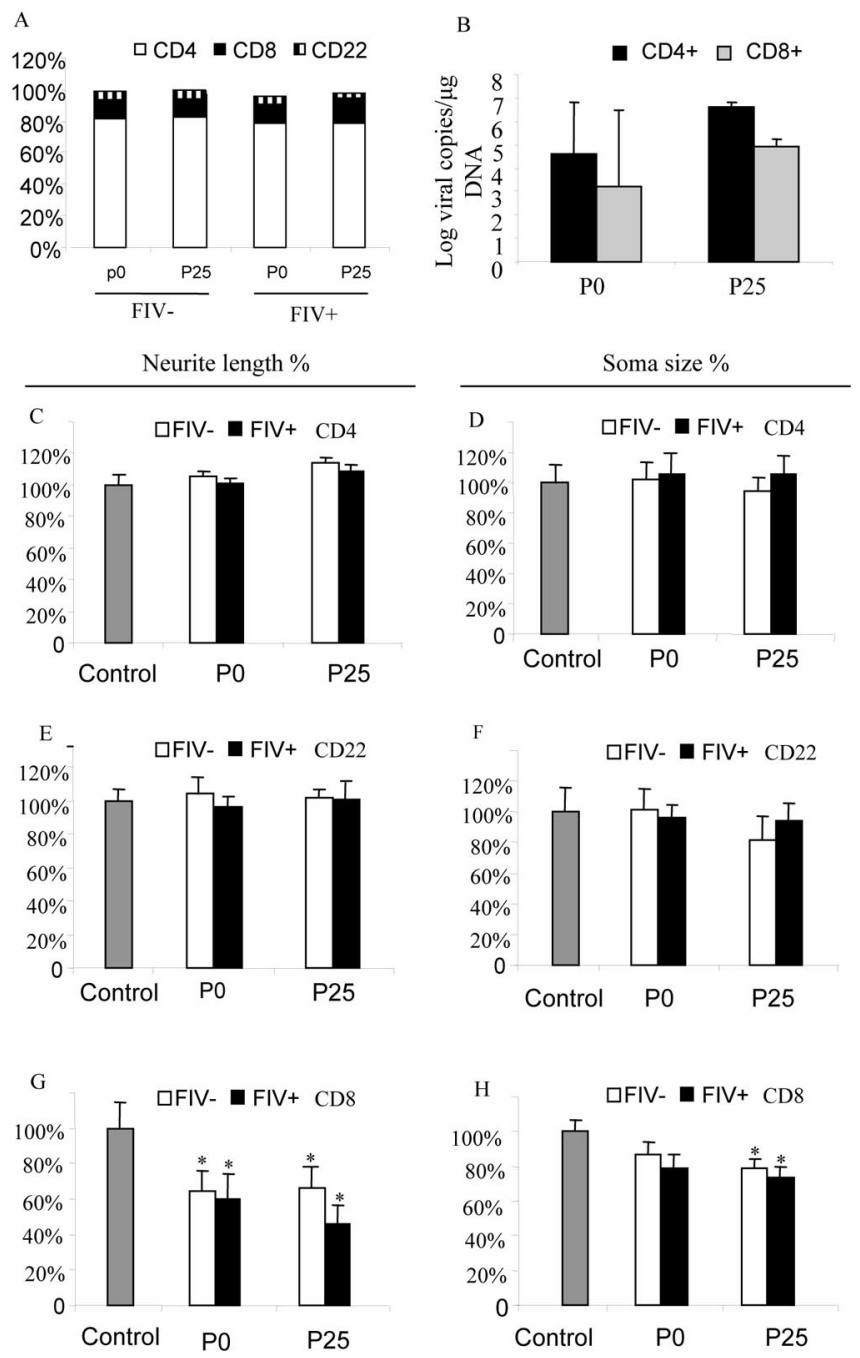

Figure 4. Effects of lymphocyte subsets on DRG neurons. $A$, FACS analyses revealed differential proportions of $C D 4+, C D 8+$, and $C D 22+$ lymphocyte populations in total cultured lymphocytes applied to DRG cultures. $\boldsymbol{B}$, Proviral load was detected in FIV-infected CD4 and CD8 $T$ cells, showing CD4 + T cells had higher levels of FIV provirus and that PMA stimulation enhanced the virus infection. CD4 + T cell or CD22 + B cell treatments did not cause retraction of neurite length $(\boldsymbol{C}, \boldsymbol{E})$ (untreated control DRG cultures, $198 \pm 27 \mu \mathrm{m}$; mean $\pm \mathrm{SEM}$ ) or soma size atrophy $(\boldsymbol{D}, \boldsymbol{F})$ (untreated control DRG cultures, $2043 \pm 164 \mu \mathrm{m}^{2}$; mean \pm SEM). $\boldsymbol{G}$, FIV-infected and uninfected CD8 + T cells induced DRG neuronal injury terms of retraction of neurite length regardless of PMA stimulation. $\boldsymbol{H}$, Neuronal soma atrophy was caused by PMAstimulated CD8 $+\mathrm{T}$ cells, regardless of FIV infection status (Bonferroni's multiple comparison test; $\left.{ }^{*} p<0.05\right)$.

pared with the neuronal expression of CD40. Among the CD3+ T lymphocytes infiltrating DRGs from FIV-infected animals, a subset of these cells also expressed CD154 (Fig. 5D). Similarly, neurons in DRG cultures expressed CD40 molecules (data not shown). However, an increase in CD154 transcript levels was observed in DRGs from FIV-infected animals compared with uninfected animals $(p<0.05)$ (data not shown). Thus, CD40 might serve as a receptor by which neuronal injury occurred during FIV infection.

To investigate further the mechanism underlying neuronal injury caused by CD8 $+\mathrm{T}$ lymphocyte treatment, anti-CD154 antibody pretreated CD8 + T lymphocytes, anti-CD154 antibody, or recombinant human CD154 peptide were applied to DRG cultures for $48 \mathrm{~h}$. Anti-CD154 antibody treatment of CD8+ $\mathrm{T}$ lymphocytes significantly attenuated the neuronal injury in 

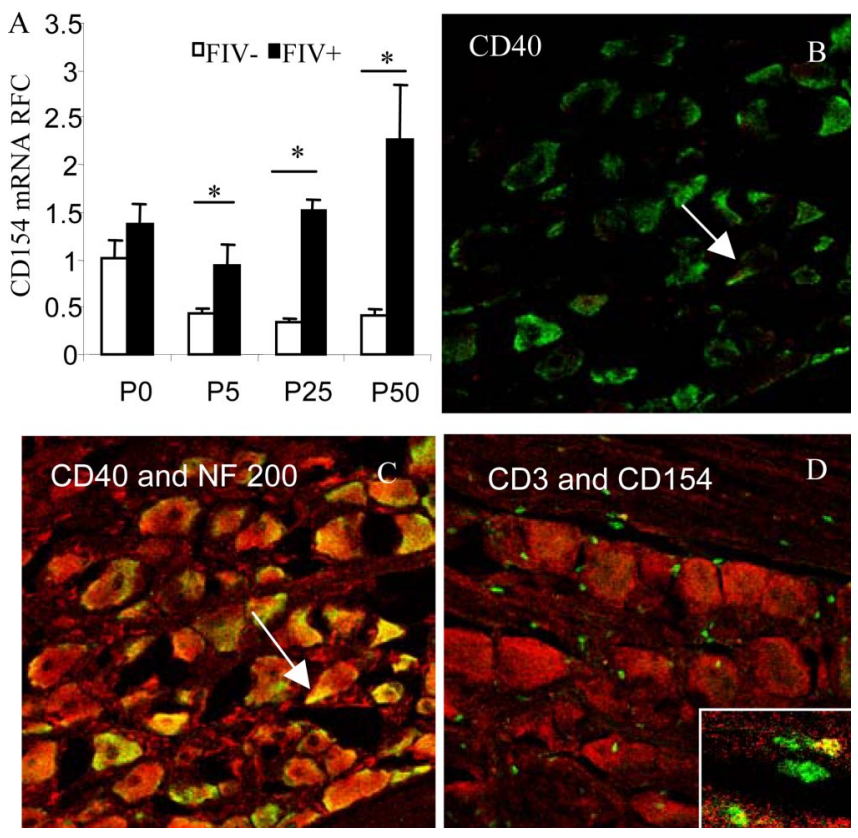

Figure 5. Expression of CD40 and CD154 in DRGs from FIV-infected animals. A, FIV infection increased CD154 transcript abundance in cultured PBLs compared with uninfected PBLs. Conversely, PMA decreased CD154 expression in uninfected PBLs. B, CD40 immunoreactive cells (green, arrows) were colocalized with NF200 immunoreactive neurons ( $\boldsymbol{C}$, yellow, arrow) in DRGs from FIV-infected animals. $\boldsymbol{D}$, Infiltrating CD3 + T cells (green) were expressed CD154 (yellow) (Student's $t$ test; ${ }^{*} p<0.05$ ).
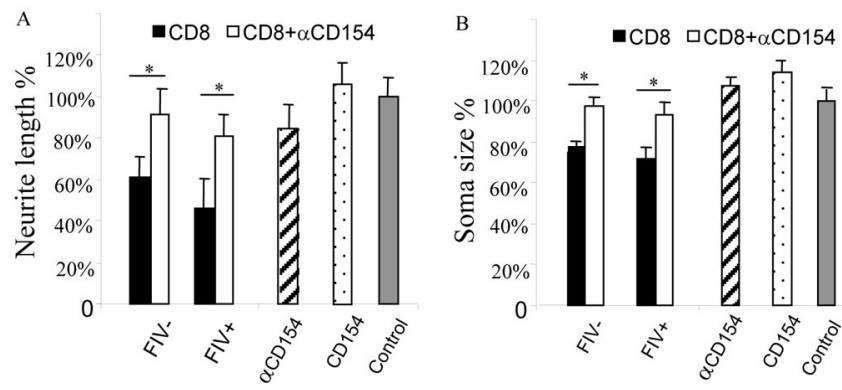

Figure 6. Inhibition of DRG neuronal injury by CD154 antibody. Pretreatment with CD154 antibody prevented neurite retraction $(\boldsymbol{A})$ (neurite length in untreated control DRG cultures, $209.1 \pm 26 \mu \mathrm{m}$; mean \pm SEM) and neuronal soma atrophy (B) (untreated control DRG cultures, $1836 \pm 78 \mu \mathrm{m}^{2}$; mean \pm SEM) caused by (D8 + T cells. In contrast, CD154 antibody or recombinant CD154 peptide treatment of DRG cultures had no effects on neuronal viability (Bonferroni's multiple comparison test; ${ }^{*} p<0.05$ ).

terms of neurite length (Fig. 6A) and soma size (Fig. 6B) compared with untreated CD8 + T lymphocytes with or without PMA stimulation regardless of FIV infection. Anti-CD154 antibody and recombinant human CD154 peptide treatment of DRG cultures had no effect on neuronal viability in terms of neurite length retraction and soma atrophy (Fig. 6A,B). These findings implied that DRG neuronal injury induced by FIV-infected and uninfected CD8 + T cells primarily resulted from CD40-CD154 interaction between neurons and CD8 $+\mathrm{T}$ cells, respectively.

\section{Discussion}

In the present study, we report that DRG neurons were injured and killed by FIV-infected and activated lymphocytes through a mechanism that required cell contact and involved CD154. Damage to small-diameter axons in peripheral nerves and DRG neurons are the hallmarks of HIV-1 associated DSP (Bradley et al.,
1998; Araujo et al., 2000). Nonetheless, little is known about the contribution of infiltrating lymphocytes in terms of neuronal injury in DRGs of HIV-infected patients with DSP. Using the FIV animal model, this is the first report of activated $\mathrm{T}$ cell-related cytotoxicity involving DRG neurons, and moreover, concurrent FIV infection of lymphocytes enhanced neurotoxicity. Indeed, the CD8 + T cell subset was the principal effector of DRG neuronal injury, in keeping with the rise in CD8 + T lymphocytes during lentivirus infections (Fig. 1).

Previous studies have shown that T cells infiltrate the DRG during HIV infection (Esiri et al., 1993), although their actions have not been investigated in the past. Infiltrating $\mathrm{T}$ cells enter the DRG because of the comparative absence of the blood nerve barrier at this site. In our study, numerous CD3 + T cells were detectable in DRGs from FIV-infected animals compared with those from uninfected animals. Moreover, the present FIVinfected animals exhibited selective loss of small-diameter axons in sural nerves, in keeping with studies of HIV-related DSP (Pardo et al., 2001). FIV-infected PBLs, with or without PMA stimulation, were particularly toxic to DRG neurons in terms of retraction of neurite length, neuronal soma atrophy, and loss when cocultured with syngeneic DRGs. These findings are consistent with previous reports that activated $\mathrm{T}$ cells could injure neurons in both syngeneic and allogeneic mechanisms in vitro (Manning et al., 1987; Rall et al., 1995; Medana et al., 2001a; Giuliani et al., 2003). HIV infection can also elicit autoreactive $\mathrm{T}$ cell responses in the circulation (Veronese et al., 1996) and in the brains of infected hosts (Lin et al., 2005); these findings resembled the marked influx and adverse effects of T cells in DRGs of FIV-infected animals, whereas the few resident $T$ cells in DRGs of healthy cats did not exert deleterious effects on neurons. Soluble factors have also been demonstrated to contribute to DRG neuron injury (Nagano et al., 1996). However, in the present studies, we observed neuronal soma atrophy alone with no effects on neurite length and neuronal survival mediated by supernatants with or without high levels FIV, suggesting that the effects of PMA might be contributing to soma atrophy. This notion is supported by the evidence that HIV-infected T cells did not release soluble neurotoxic factors (other than viral particles) unlike HIV-infected macrophages (Xu et al., 2004). Our findings suggest that concomitant differing mechanisms of neuronal injury occur in the present system. For example, neuronal soma atrophy occurred without neurite retraction (Fig. 3) and, vice versa, neurite retraction was present without soma atrophy (Fig. 2). These observations emphasize the complexity of lentivirus-induced neuronal damage and death, but they also imply that axonal injury and loss observed in HIV-related DSP may reflect a process by which axons and neurites retract because of events occurring at the level of the neuronal soma.

In the CNS of HIV-infected humans and simian immunodeficiency virus (SIV)-infected animals, numerous infiltrating $\mathrm{T}$ lymphocytes have been identified (Weidenheim et al., 1993; Boche et al., 1999; Neuenburg et al., 2005), which are comprised of both CD8 + and CD4+ T cells (Petito et al., 2003; Kim et al., 2004). However, activated CD8 $+\mathrm{T}$ cells represent the major $\mathrm{T}$ cell subset in the HIV- or SIV-infected CNS (Marcondes et al., 2001; Shacklett et al., 2004). In the PNS, T cell subsets have not been identified in peripheral nerves and DRG of HIV-infected patients and of FIV-infected animals because of limited speciesspecific tools (e.g., antibodies). Nonetheless, both FIV-infected and uninfected $\mathrm{CD} 8+\mathrm{T}$ cells, rather than $\mathrm{CD} 4+\mathrm{T}$ cells and CD22 + B cells, exhibited cytotoxicity to DRG neurons in the current study. This finding may reflect that activated CD8+ T 
cells exhibiting a distinct clonal repertoire with the capacity to cause neurological damage (Marcondes et al., 2001; Shacklett et al., 2004), although HIV-specific CD8 + T cells play a central role in immune response against viruses.

Many types of tissue injuries and immune-mediated pathologies are reported to involve CD40-CD154 interactions, which induce cytokine release and apoptosis (Szocinski et al., 2002; Airoldi et al., 2003; Gotoh et al., 2004). CD40 contains a cytoplasmic motif reminiscent of the domain that mediates TNF receptor and CD95-dependent apoptosis. CD40 is not only expressed on B cells and macrophage and dendrite cells but also on nonimmune cells such as endothelial cells (Galy and Spits, 1992), normal and neoplastic thyroid cells (Smith et al., 1999), and carcinomas (Sugimoto et al., 1999). The expression of CD40 on feline DRG neurons in the present study is supported by studies showing that CD40 is expressed and functional on neuronal cells (Tan et al., 2002). CD154 is the cognate ligand for CD40 and is principally expressed on activated T cells. FIV infection markedly increased CD154 expression on T cells both in vivo and in vitro, similar to that observed in HIV infection (Zhang et al., 2004), although PMA decreased the CD154 expression on uninfected T cells, including CD4+ and CD8 $+\mathrm{T}$ cells in vitro, which was correlated with the degree of neuronal injury. Functional blockage of CD154 expression on CD8 T cells significantly attenuated the neuronal injury induced by FIV-infected and uninfected CD8+ $\mathrm{T}$ cells in terms of neurite length and soma size, indicating that engagement of CD40 expressed on neurons by CD154 expressed by CD $8+$ T cells caused DRG neuronal injury. However, FIVinfected and uninfected CD4 + T cells did not induce DRG neuronal injury despite expressing CD154, and neither did soluble recombinant CD154. These latter data indicate that other costimulatory factors are required during the process of CD40CD154 interaction leading to neuronal injury. It is clear that lentivirus-infected macrophages are also present in DRGs and are associated with the development of DSP (Bradley et al., 1998; Kennedy et al., 2004). Macrophages can also function as cytotoxic effectors of neuronal injury in both the PNS and CNS, but our studies sought to focus on the actions of the numerous infiltrating T cells. Moreover, minimal CD40 was expressed on CD18+ macrophages in DRGs, underscoring the direct interaction between CD154 on T cells and CD40 on neurons as a mechanism of neuronal injury.

Previous studies have demonstrated that during the course of the disease, immunity against HIV cross-reacts with suppressor $\mathrm{T}$ cell clones, disrupting the function of the helper $\mathrm{T}$ cell repertoire and resulting in autoimmunity (Hoffmann, 1995). HIV-infected patients have circulating autoreactive cytotoxic $\mathrm{T}$ lymphocyte (CTL) and infiltrating CD8 + T cells in the brain, which recognize host and not viral peptides (Salemi et al., 1995; di Marzo Veronese et al., 1996; Miller et al., 2004; Lin et al., 2005). There are reports describing neurons that express MHC-I molecules (Rall et al., 1995; Abendroth et al., 2000), which are necessary for CTL recognition of target cells. Therefore, we predict that MHC-I expressed on neurons may also be necessary for CD8 + T cellmediated neuronal injury through CD40-CD154 interaction. In contrast, FIV-infected and uninfected CD8 $+\mathrm{T}$ cells may also interact through other mechanisms, leading to macrophage release of neurotoxins (Gurlo and von Grafenstein, 2003) such as nitric oxide, which was found to kill DRG neurons during FIV infection (Zhu et al., 2005). Nonetheless, the identification of $\mathrm{CD} 8+\mathrm{T}$ cells as major effectors of neuronal damage and death during lentivirus-induced DSP provides new insights into devel- oping therapeutic strategies for lentivirus-related distal sensory polyneuropathy.

\section{References}

Abendroth A, Simmons A, Efstathiou S, Pereira RA (2000) Infection with an $\mathrm{H} 2$ recombinant herpes simplex virus vector results in expression of MHC class I antigens on the surfaces of human neuroblastoma cells in vitro and mouse sensory neurons in vivo. J Gen Virol 81:2375-2383.

Airoldi I, Lualdi S, Bruno S, Raffaghello L, Occhino M, Gambini C, Pistoia V, Corrias MV (2003) Expression of costimulatory molecules in human neuroblastoma. Evidence that CD40+ neuroblastoma cells undergo apoptosis following interaction with CD40L. Br J Cancer 88:1527-1536.

Araujo AP, Nascimento OJ, Garcia OS (2000) Distal sensory polyneuropathy in a cohort of HIV-infected children over five years of age. Pediatrics 106:E35.

Bien CG, Bauer J, Deckwerth TL, Wiendl H, Deckert M, Wiestler OD, Schramm J, Elger CE, Lassmann H (2002) Destruction of neurons by cytotoxic T cells: a new pathogenic mechanism in Rasmussen's encephalitis. Ann Neurol 51:311-318.

Boche D, Khatissian E, Gray F, Falanga P, Montagnier L, Hurtrel B (1999) Viral load and neuropathology in the SIV model. J Neurovirol 5:232-240.

Bradley WG, Shapshak P, Delgado S, Nagano I, Stewart R, Rocha B (1998) Morphometric analysis of the peripheral neuropathy of AIDS. Muscle Nerve 21:1188-1195.

Brinley Jr FJ, Pardo CA, Verma A (2001) Human immunodeficiency virus and the peripheral nervous system workshop. Arch Neurol 58:1561-1566.

Brunner D, Pedersen NC (1989) Infection of peritoneal macrophages in vitro and in vivo with feline immunodeficiency virus. J Virol 63:5483-5488.

Daoussis D, Andonopoulos AP, Liossis SN (2004) Targeting CD40L: a promising therapeutic approach. Clin Diagn Lab Immunol 11:635-641.

di Marzo Veronese F, Arnott D, Barnaba V, Loftus DJ, Sakaguchi K, Thompson CB, Salemi S, Mastroianni C, Sette A, Shabanowitz J, Hunt DF, Appella E (1996) Autoreactive cytotoxic T lymphocytes in human immunodeficiency virus type 1-infected subjects. J Exp Med 183:2509-2516.

Dow SW, Poss ML, Hoover EA (1990) Feline immunodeficiency virus: a neurotropic lentivirus. J Acquir Immune Defic Syndr 3:658-668.

Esiri MM, Morris CS, Millard PR (1993) Sensory and sympathetic ganglia in HIV-1 infection: immunocytochemical demonstration of HIV-1 viral antigens, increased MHC class II antigen expression and mild reactive inflammation. J Neurol Sci 114:178-187.

Galy AH, Spits H (1992) CD40 is functionally expressed on human thymic epithelial cells. J Immunol 149:775-782.

Giuliani F, Goodyer CG, Antel JP, Yong VW (2003) Vulnerability of human neurons to T cell-mediated cytotoxicity. J Immunol 171:368-379.

Gotoh H, Kawaguchi Y, Harigai M, Hara M, Saito S, Yamaguchi T, Shimada K, Kawamoto M, Tomatsu T, Kamatani N (2004) Increased CD40 expression on articular chondrocytes from patients with rheumatoid arthritis: contribution to production of cytokines and matrix metalloproteinases. J Rheumatol 31:1506-1512.

Gurlo T, von Grafenstein H (2003) Antigen-independent cross-talk between macrophages and CD8 + T cells facilitates their cooperation during target destruction. Int Immunol 15:1063-1071.

Hannila SS, Kawaja MD (2003) Distribution of central sensory axons in transgenic mice overexpressing nerve growth factor and lacking functional p75 neurotrophin receptor expression. Eur J Neurosci 18:312-322.

Hoffmann GW (1995) The T cell receptor and AIDS pathogenesis. Scand J Immunol 41:331-337.

Ichiki Y, Aoki CA, Bowlus CL, Shimoda S, Ishibashi H, Gershwin ME (2005) $\mathrm{T}$ cell immunity in autoimmune hepatitis. Autoimmun Rev 4:315-321.

Johnston JB, Power C (2002) Feline immunodeficiency virus xenoinfection: the role of chemokine receptors and envelope diversity. J Virol 76:3626-3636

Johnston JB, Jiang Y, van Marle G, Mayne MB, Ni W, Holden J, McArthur JC, Power C (2000) Lentivirus infection in the brain induces matrix metalloproteinase expression: role of envelope diversity. J Virol 74:7211-7220.

Jones G, Zhu Y, Silva C, Tsutsui S, Pardo CA, Keppler OT, McArthur JC, Power C (2005) Peripheral nerve-derived HIV-1 is predominantly CCR5-dependent and causes neuronal degeneration and neuroinflammation. Virology 334:178-193.

Kennedy JM, Hoke A, Zhu Y, Johnston JB, van Marle G, Silva C, Zochodne 
DW, Power C (2004) Peripheral neuropathy in lentivirus infection: evidence of inflammation and axonal injury. Aids 18:1241-1250.

Keswani SC, Hoke A (2003) Incidence of and risk factors for HIV-associated distal sensory polyneuropathy. Neurology 61:279, 279-280.

Kim WK, Corey S, Chesney G, Knight H, Klumpp S, Wuthrich C, Letvin N, Koralnik I, Lackner A, Veasey R, Williams K (2004) Identification of T lymphocytes in simian immunodeficiency virus encephalitis: distribution of CD8 + T cells in association with central nervous system vessels and virus. J Neurovirol 10:315-325.

Lin WL, Fincke JE, Sharer LR, Monos DS, Lu S, Gaughan J, Platsoucas CD, Oleszak EL (2005) Oligoclonal T cells are infiltrating the brains of children with AIDS: sequence analysis reveals high proportions of identical beta-chain T-cell receptor transcripts. Clin Exp Immunol 141:338-356.

Manning PT, Johnson Jr EM, Wilcox CL, Palmatier MA, Russell JH (1987) MHC-specific cytotoxic T lymphocyte killing of dissociated sympathetic neuronal cultures. Am J Pathol 128:395-409.

Marcondes MC, Burudi EM, Huitron-Resendiz S, Sanchez-Alavez M, Watry D, Zandonatti M, Henriksen SJ, Fox HS (2001) Highly activated CD8(+) T cells in the brain correlate with early central nervous system dysfunction in simian immunodeficiency virus infection. J Immunol 167:5429-5438.

Medana I, Martinic MA, Wekerle H, Neumann H (2001a) Transection of major histocompatibility complex class I-induced neurites by cytotoxic $\mathrm{T}$ lymphocytes. Am J Pathol 159:809-815.

Medana I, Li Z, Flugel A, Tschopp J, Wekerle H, Neumann H (2001b) Fas ligand (CD95L) protects neurons against perforin-mediated T lymphocyte cytotoxicity. J Immunol 167:674-681.

Miller RF, Isaacson PG, Hall-Craggs M, Lucas S, Gray F, Scaravilli F, An SF (2004) Cerebral CD8 + lymphocytosis in HIV-1 infected patients with immune restoration induced by HAART. Acta Neuropathol (Berl) 108:17-23.

Nagano I, Shapshak P, Yoshioka M, Xin K, Nakamura S, Bradley WG (1996) Increased NADPH-diaphorase reactivity and cytokine expression in dorsal root ganglia in acquired immunodeficiency syndrome. J Neurol Sci 136:117-128.

Neuenburg JK, Cho TA, Nilsson A, Bredt BM, Hebert SJ, Grant RM, Price RW (2005) T-cell activation and memory phenotypes in cerebrospinal fluid during HIV infection. J Acquir Immune Defic Syndr 39:16-22.

Nitsch R, Pohl EE, Smorodchenko A, Infante-Duarte C, Aktas O, Zipp F (2004) Direct impact of T cells on neurons revealed by two-photon microscopy in living brain tissue. J Neurosci 24:2458-2464.

Pandya R, Krentz HB, Gill MJ, Power C (2005) HIV-related neurological syndromes reduce health-related quality of life. Can J Neurol Sci 32:201-204

Pardo CA, McArthur JC, Griffin JW (2001) HIV neuropathy: insights in the pathology of HIV peripheral nerve disease. J Peripher Nerv Syst 6:21-27.

Petito CK, Adkins B, McCarthy M, Roberts B, Khamis I (2003) CD4+ and $\mathrm{CD} 8+$ cells accumulate in the brains of acquired immunodeficiency syndrome patients with human immunodeficiency virus encephalitis. J Neurovirol 9:36-44.

Power C, Buist R, Johnston JB, Del Bigio MR, Ni W, Dawood MR, Peeling J (1998) Neurovirulence in feline immunodeficiency virus-infected neonatal cats is viral strain specific and dependent on systemic immune suppression. J Virol 72:9109-9115.

Power C, Henry S, Del Bigio MR, Larsen PH, Corbett D, Imai Y, Yong VW, Peeling J (2003) Intracerebral hemorrhage induces macrophage activation and matrix metalloproteinases. Ann Neurol 53:731-742.

Rall GF, Mucke L, Oldstone MB (1995) Consequences of cytotoxic T lym- phocyte interaction with major histocompatibility complex class I-expressing neurons in vivo. J Exp Med 182:1201-1212.

Riccieri V, Parisi G, Spadaro A, Scrivo R, Barone F, Moretti T, Bernardini G, Strom R, Taccari E, Valesini G (2005) Reduced circulating natural killer $\mathrm{T}$ cells and gamma/delta $\mathrm{T}$ cells in patients with systemic sclerosis. J Rheumatol 32:283-286.

Salemi S, Caporossi AP, Boffa L, Longobardi MG, Barnaba V (1995) HIVgp120 activates autoreactive CD4-specific T cell responses by unveiling of hidden CD4 peptides during processing. J Exp Med 181:2253-2257.

Shacklett BL, Cox CA, Wilkens DT, Karl Karlsson R, Nilsson A, Nixon DF, Price RW (2004) Increased adhesion molecule and chemokine receptor expression on CD8 + T cells trafficking to cerebrospinal fluid in HIV-1 infection. J Infect Dis 189:2202-2212.

Smith TJ, Sciaky D, Phipps RP, Jennings TA (1999) CD40 expression in human thyroid tissue: evidence for involvement of multiple cell types in autoimmune and neoplastic diseases. Thyroid 9:749-755.

Sugimoto K, Shiraki K, Ito T, Fujikawa K, Takase K, Tameda Y, Moriyama M, Nakano T (1999) Expression of functional CD40 in human hepatocellular carcinoma. Hepatology 30:920-926.

Szocinski JL, Khaled AR, Hixon J, Halverson D, Funakoshi S, Fanslow WC, Boyd A, Taub DD, Durum SK, Siegall CB, Longo DL, Murphy WJ (2002) Activation-induced cell death of aggressive histology lymphomas by CD40 stimulation: induction of bax. Blood 100:217-223.

Tan J, Town T, Mori T, Obregon D, Wu Y, DelleDonne A, Rojiani A, Crawford F, Flavell RA, Mullan M (2002) CD40 is expressed and functional on neuronal cells. EMBO J 21:643-652.

Toubi E, Shoenfeld Y (2004) The role of CD40-CD154 interactions in autoimmunity and the benefit of disrupting this pathway. Autoimmunity 37:457-464.

van Marle G, Rourke SB, Zhang K, Silva C, Ethier J, Gill MJ, Power C (2002) HIV dementia patients exhibit reduced viral neutralization and increased envelope sequence diversity in blood and brain. AIDS 16:1905-1914.

Verma A (2001) Epidemiology and clinical features of HIV-1 associated neuropathies. J Peripher Nerv Syst 6:8-13.

Veronese ML, Schichman SA, Croce CM (1996) Molecular diagnosis of lymphoma. Curr Opin Oncol 8:346-352.

Weidenheim KM, Epshteyn I, Lyman WD (1993) Immunocytochemical identification of T-cells in HIV-1 encephalitis: implications for pathogenesis of CNS disease. Mod Pathol 6:167-174.

Willett BJ, Picard L, Hosie MJ, Turner JD, Adema K, Clapham PR (1997) Shared usage of the chemokine receptor CXCR4 by the feline and human immunodeficiency viruses. J Virol 71:6407-6415.

Xu Y, Kulkosky J, Acheampong E, Nunnari G, Sullivan J, Pomerantz RJ (2004) HIV-1-mediated apoptosis of neuronal cells: proximal molecular mechanisms of HIV-1-induced encephalopathy. Proc Natl Acad Sci USA 101:7070-7075.

Zhang R, Fichtenbaum CJ, Hildeman DA, Lifson JD, Chougnet C (2004) CD40 ligand dysregulation in HIV infection: HIV glycoprotein 120 inhibits signaling cascades upstream of CD40 ligand transcription. J Immunol 172:2678-2686.

Zhu Y, Jones G, Tsutsui S, Opii W, Liu S, Silva C, Butterfield DA, Power C (2005) Lentivirus infection causes neuroinflammation and neuronal injury in dorsal root ganglia: pathogenic effects of STAT-1 and inducible nitric oxide synthase. J Immunol 175:1118-1126.

Zochodne DW, Misra M, Cheng C, Sun H (1997) Inhibition of nitric oxide synthase enhances peripheral nerve regeneration in mice. Neurosci Lett 228:71-74. 